Network Approaches to Representing and Understanding Personality Dynamics

Emorie D Beck and Joshua J Jackson

Washington University in St. Louis 


\begin{abstract}
From its emergence at the beginning of the $20^{\text {th }}$ century, personality scientists pursued two goals - a nomothetic approach that investigated the structure of individual differences between people in a population and an idiographic approach that explored variation within a person relative to him or herself. Implicit in both was an assumption that dynamic processes underlay the emergence of personality within and across people, but available methods at the time precluded testing dynamic questions. In this chapter, we first track how the history of both nomothetic and idiographic perspectives impacted the study of personality structure and dynamics. Next, we review findings and unanswered contemporary questions regarding nomothetic and idiographic structure, processes, and dynamics. Finally, we conclude by arguing for an idiographic network approach to understanding personality, based in dynamic systems theory. We provide both theoretical questions for future research, some of which were proposed by early personality theorists but progressed slowly due to a lack of adequate methods, as well as cutting-edge techniques for actually testing them. We believe these methods are capable of moving the study of personality dynamics - and personality more broadly -- forward.
\end{abstract}

Keywords: personality, dynamics, structure, process, idiographic 


\section{Network Approaches to Representing and Understanding Personality Dynamics}

From its inception, personality psychology had at least two distinct goals - to describe how people differed from one another on shared attributes (a nomothetic approach) and to describe and explain individuals holistically (an idiographic approach), with a focus on why people behaved similarly or differently across time and contexts. The former focused on understanding what underlies the stability of behavior across people, time, and situations. The latter meant to understand the dynamics and variability of behavior within and across people, time, and situations. The distinction between nomothetic and idiographic approaches was reflected in methodological differences within the field, still seen today in the tension between qualitative and quantitative approaches. While nomothetic approaches have relied on quantitative models, idiographic approaches primarily exist in psychobiography and clinical work (e.g. Barenbaum \& Winter, 2008; McAdams, 1997). Recent methodological advances, however, suggest that idiographic approaches and the study of personality dynamics are poised for a resurgence using rigorous methodological and quantitative techniques.

Nomothetic approaches dominate the study of personality psychology, partly due to advanced assessment techniques and statistical methods that were (historically) more appropriate for nomothetic, compared to idiographic, questions. Perhaps no technological advance fueled the study of individual differences more than the introduction of psychometric techniques and factor analysis in the beginning of the $20^{\text {th }}$ century. In addition to the rise of factor analysis contributing to the adoption of personality traits as the key units of personality psychology, two founding fathers of personality, Gordon W. Allport and Raymond B. Cattell, adopted traits into their theoretical and empirical studies of personality. Understanding personality in terms of trait units opened up many new questions regarding the number of traits, the nature of those traits, and the 
organization of traits. Evidence that traits show long-term stability and predict numerous life outcomes (e.g., Beck \& Jackson, 2020a Jackson, Connolly, Garrison, Leveille, \& Connolly, 2015; Specht, Egloff \& Schmukle, 2011; Weston, Hill, \& Jackson, 2015) has cemented the nomothetic, trait approach as the dominant paradigm within personality psychology.

Unlike nomothetic approaches, the idiographic study of personality structure, dynamics, and variability did not benefit from the same advancement in strong methodological tools. Although both Allport and Cattell were also strong advocates of the study of idiographic structure and dynamics, the lack of available methods for testing these questions contributed to a decrease in popularity of idiographic methods within the field of personality. Recently, however, advances in measurement and modeling techniques have sparked interest in investigating dynamics.

In the present paper, we focus on the study of dynamics in the field of personality. First, we outline its historical precursors and roots, discussing the promises early thinking on dynamics and idiographic methods offered the field as well as early challenges it faced. Second, we discuss recent developments in methodology, including the introduction of experience sampling methods (ESM) and time series statistical approaches that brought personality dynamics back to the fore in personality. Finally, we chart our vision for the future of the study of personality dynamics in psychology, highlighting theoretical and statistical tools from other areas of science and psychology that offer promising new insights in personality.

\section{Early Thinking on Dynamics}

Before beginning a discussion of the history of dynamics in personality, it is imperative to define what we mean when we say dynamics, which is a term that has been overused and misappropriated to the point that the term has nearly lost meaning. In this chapter, when we refer 
to dynamics, we refer to relationships among psychological processes considered in real, or continuous, time terms, which is also the spirit of the dictionary definition of dynamics.

Moreover, we believe that continuous time implies changes that occur over relatively short time periods, from milliseconds to days, not months to years. To us, the former is dynamics and the latter is better considered (longitudinal) change.

\section{Allport: Theorizing on Dynamic Organization}

The early $20^{\text {th }}$ century saw both the emergence of personality as a discipline as well as formalization of foundational ideas concerning it. One early transformative idea concerned what the "units" of personality should be. The "father" of personality, Gordon W. Allport, put forth several elegant arguments for traits as the unit of personality, including writing the first American doctoral thesis on personality entitled "An Experimental Study of the Traits of Personality" in 1922. Of course, choosing a unit does not mean that there is a single way to define it; thus, it was not until the 1936 publication of the lexical hypothesis that traits began to be adopted more broadly as the units of personality as the field converged on a definition of traits (Allport \& Odbert, 1936). According to the lexical hypothesis, to find the terms that describe how individuals differ from one another (i.e. traits), one can turn to the everyday language people use to describe themselves and others. Self-ratings of these trait adjectives would become the precursor of nomothetic personality trait inventories that make up the bulk of personality research today.

The adoption of personality traits according to the lexical hypothesis gave nomothetic approaches and the study of between-person personality structure an early advantage over idiographic approaches and the study of dynamics. To Allport, what these nomothetic approaches captured were not dynamic, causal traits. Instead, these "common" traits capture the 
measurable aspects of complex, individual (or idiographic) traits. In other words, to Allport (1937), traits existed at two levels - at the level of the individual and the level of the population but the "existence" of the two are not mutually exclusive.

Importantly for the study of personality dynamics, only idiographic traits were dynamic and causal. As he defined it, personality was "the dynamic organization within the individual of those psychophysical systems that determine his unique adjustments to his environment" (Allport, 1937, p. 48; emphasis added). Each piece of this definition warrants unpacking as it has directions for how personality dynamics could be studied. First, the definition explicitly uses the word dynamic, implying that personality is not a static factor over time. Second, his definition states that personality is an organization, or structure. Third, personality exists within the individual, or idiographically. Fourth, what makes up the structure of personality is (psychophysical) systems, meaning that the structure (or the organization of features that are relevant) within an individual may be different over time and across situations. Fifth, the use of the word "determine" underscores Allport's contention that idiographic personality traits are causal. Finally, every individual has unique adjustments or variability that are partially dependent on their environment. In other words, transactions with the environment are also best considered idiographically.

\section{Cattell: Formalizing Dynamic Organization}

Although Allport provided a strong theoretical framework for understanding personality both within- and between-person, he focused on methods that captured the static structure of personality, rather than the methods necessary for a comprehensive study of dynamics. For that, we turn to Raymond B. Cattell. 
In the latter half of the $20^{\text {th }}$ century, Cattell (1957) wrote and published a seminal book Personality and Motivation: Structure and Measurement that introduced several methodological and conceptual ideas that helped personality move towards a science of dynamics. In introducing the data box, Cattell (1946a) argued that persons could be conceptualized into 3-dimensions that indexed people $\left(\mathrm{P}_{1}\right.$ to $\left.\mathrm{P}_{\mathrm{N}}\right)$, variables $\left(\mathrm{X}_{1}\right.$ to $\left.\mathrm{X}_{\mathrm{p}}\right)$, and occasions or time $\left(\mathrm{T}_{1}\right.$ to $\left.\mathrm{T}_{\mathrm{t}}\right)$. The questions asked and answered by personality psychology, he argued, depended on how one sliced the data box. For example, typical nomothetic questions focus on the person $(\mathrm{P})$ and variable $(\mathrm{X})$ dimensions and collapse across the occasion (T) dimension, thereby addressing the question of the structure of individual differences within a population of people, which he termed $R$ technique (See Figure 1a).

R-Technique

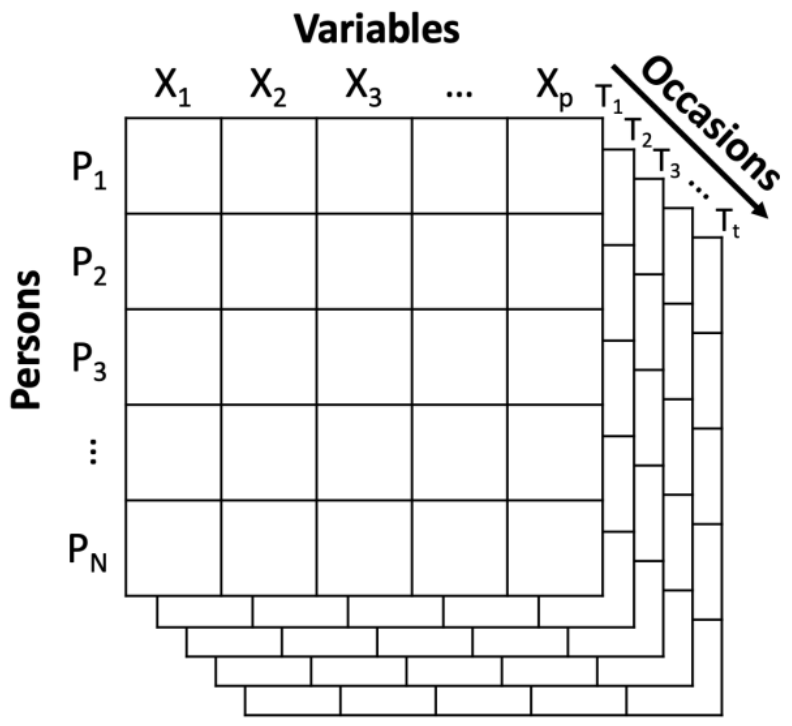

P-Technique Variables

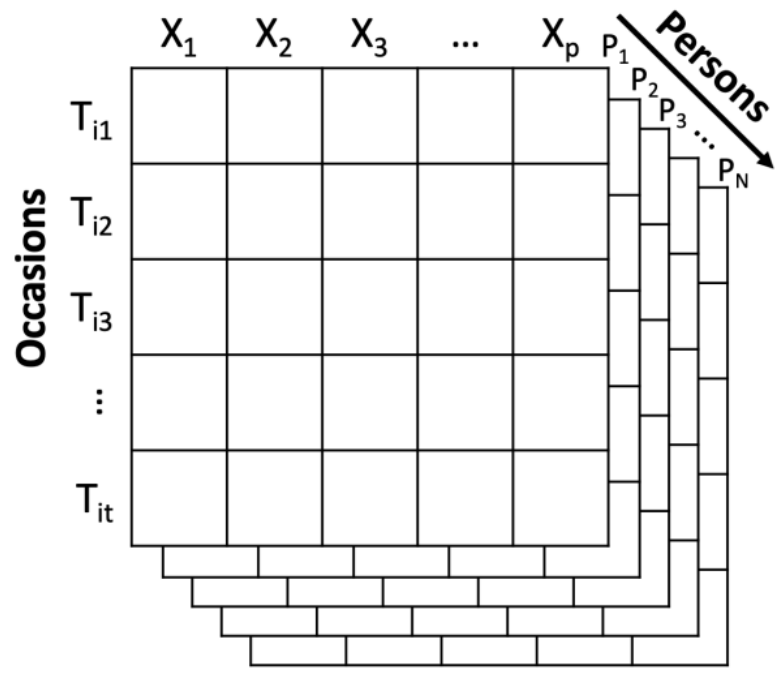

Figure 1. Two ways to "slice" the Cattell's (1946b) data box to produce R-technique (nomothetic) and P-technique (idiographic) factor analytic structures. In R-technique, one collapses across or slices across the occasions dimension (T) to get the common structure of variables across people, perhaps solely applicable to a particular time or population. In Ptechnique, one slices across individuals to find the unique structure of variables within a particular person across time. 
Cattell was a pioneer in moving both the science of between person differences and the study of within-person variability forward. He noted that by slicing the data box into variable (X) and occasion (T) dimensions and fixing the person dimension, one can capture the unique structure of individual differences for a single person - that is, the within-person structure of personality (See Figure 1b). Cattell formalized these under the umbrella of $P$-technique, in which factor analytic models were applied to X x T matrices for individual people (Cattell, 1943).

\section{Structure versus Dynamics: The Person-Situation Debate}

As the mid $20^{\text {th }}$ century progressed, personality scientists continued to pursue questions pertaining to the organization and number of common traits nomothetically. Cattell and others proposed models of varying numbers and organizations of traits thought to capture betweenperson differences. Out of this intellectual climate emerged a critique of personality traits that even today has strong implications for the field. In 1968, Walter Mischel published his book Personality and Assessment, in which he argued against personality traits as the unit of personality, citing evidence that personality traits tend to correlate at most .3 with actual behavior and situations played a perhaps more important role in determining behavior. Notably, Mischel (1968) was not arguing that personality did not exist or that personality did not play a role in behavior. Instead, he argued for shifting the focus from static traits to more dynamic constructs that could account for within person fluctuations.

In the resulting Person-Situation Debate, which some argue has ended while others argue it is ongoing, personality scientists faced the challenge of demonstrating the power and utility of person-factors in predicting and explaining behaviors and outcomes. Thus, many personality scientists turned to shoring up the measurement of personality traits and trying to define the core traits that differentiated people. In this approach, the focus was on aggregating situations out of 
personality and distilling those individual differences that people carry across situations. But in Personality and Assessment, Mischel laid the groundwork for social cognitive approaches that he and others would spend the remaining 50 years of his life investigating - beyond traits, what psychological units can explain both the coherence of personality and the variability of its manifestations across situations and time? In other words, how do we build a dynamic theory of personality? Below, we will address some of the main work on social cognitive approaches and their implications for understanding personality dynamically.

\section{Social Cognitive Approaches to Personality}

Social cognitive theory. Mischel was not the only pioneer of work on the dynamic interplay between persons, situations, and behavior. Indeed, out of this increased interest in the consistency of personality across contexts and time grew a new theoretical branch of personality aimed at mapping out a dynamic theory of personality- social cognitive theories (or cognitive social learning theories, Mischel, 1973). Social cognitive theories turned traditional methods for understanding personality consistency on their heads by assuming that there was little reason to believe that personality would ever be consistent across contexts or situations. Instead, individual differences were thought to be expressed in the profile of responses in different contexts. That is, some people tended to be outgoing in a particular context, but not another. Rather than define personality from a nomothetic trait perspective using an average (expected) response collapsed across contexts, personality viewed from a social cognitive perspective was the average response within a context. What constituted a context was also an important component of discussion.

A central social cognitive theory was Bandura's Social Cognitive Theory (Bandura, 1999). Bandura emphasized that individuals are active organisms in their environments, who can choose certain responses in order to get certain results. A key component of this theory is the 
focus on bidirectional relationships between person and environment, which emphasizes the variability within a person's behavior. Depending on one's motivations, people could behave differently in the same situation. For example, one's behavior with the same friend would differ greatly when one is trying to convince the other of something than it would on average across a number of different motivational contexts. Bandura (1999) broke the person-situation interplay into three components - person-level states (cognitive, affective, and biological), behavioral patterns (more akin to traits), and environmental events.

Several components of Social Cognitive Theory have direct implications for the study of dynamics in personality. First, to Bandura, personality was the interplay of these three components. Unlike traditional trait perspectives, which put the person first, his view gave equal weight to state, person, and environmental components. Second, and just as importantly, all of the components bi-directionally influenced one another as well as themselves, which is a hallmark of dynamic theories. Third, he emphasized that objective features of imposed and selected environments are not equal to the subjectively constructed environment. That is, the experience of an environment may be quite different from the objective features that make it up, and this may very across person and across time.

Social Cognitive Theory was built on the foundational work on self-efficacy, which he defined as “beliefs in one's capabilities to organize and execute the courses of action required to produce given attainments" (Bandura, 1997, p. 3). Bandura argues that it makes little sense to construct general measures of self-efficacy as some constructed items may have little to no relevance for a given person in a given domain (Bandura, 2006). Instead, measures of selfefficacy (and by extension other psychological constructs) should be constructed for specific contexts or domains of interest and include only those components relevant to the individuals 
under study. In other words, work on self-efficacy stands apart from much of the existent research in personality by incorporating principles of idiographic measurement that is also sensitive to time and context. Importantly, these measures have oft been used to predict domain specific outcomes at levels above personality traits (Bandura, 1986; Judge, Jackson, Shaw, Scott, \& Rich, 2007).

However, despite its promises, where Social Cognitive Theory arguably is lacking is in offering a clearly testable framework for many of its propositions. First, despite its clear argument that components of self-efficacy should greatly differ across context, it is less clear whether these are supposed to be shared within contexts across individuals - that is, whether a self-efficacy scale created for a context accurately captures all individuals within it. Moreover, even if components are shared, it is not clear whether they should be exact or probabilistic matches (i.e. what are the limits of their prediction?). Second, although Social Cognitive Theory proposes the interplay of persons, situations, and behaviors, the exact mapping of those relationship is unclear. In other words, it does not provide a convincing explanation for why broad traits are not a compelling unit of personality (c.f. Jackson, Hill \& Roberts, 2012).

Conditional approaches. Another related branch of social cognitive approaches accounts for variability across contexts by borrowing from stimulus-response learning models (Wright \& Mischel, 1987). Termed “conditional approaches” to personality, these focused on if...then patterns of relationships that can vary across contexts and people (i.e. person-situation transactions). From this perspective, personality should be conceived in probabilistic relationships - the probability of certain response tendencies or behaviors $(p(\mathrm{~B}))$, the probability of certain conditions or contexts $(p(\mathrm{C}))$, and the conditional probability of a certain response tendency or behavior in a certain condition or context $(p(\mathrm{~B} \mid \mathrm{C}))$. Conditional approaches argue 
that personality researchers tended to focus just on the constant aspect of behavior where traits can be thought of as the $p(\mathrm{~B})$ component, neglecting the other components.

Conceiving of personality as sets of if...then contingencies has important implications for a dynamic understanding of personality. First, it highlights that focusing only on the constant probability of a behavior $(p(B))$ misses how that probability may change as a function of the context $(p(\mathrm{~B} \mid \mathrm{C}))$. Second, using a conditional rather than joint probability of behavior and contexts $(p(\mathrm{~B} \cap \mathrm{C}))$ highlights the importance of accounting for the base rates of both. In other words, one can take advantage of probability theory to understand how the relationship between person and environment influences behavior between people on average and within-person over time (and also partially mitigates the often computationally intractable nature of joint probabilities).

Despite the promise of conditional approaches for reconceptualizing the study of personality and situations, it has a number of limitations. First, it was limited by the available statistical methods, which did not allow for explicitly modeling dynamic processes. For example, in a seminal series of studies, children being treated for behavioral disorders at the Wediko Summer Program in New Hampshire were observed by multiple individuals who rated them on a number of dimensions across different contexts (e.g. Mischel \& Shoda, 1995; Shoda, Mischel, \& Wright., 1994; Wright \& Mischel, 1987). These studies demonstrated that children who exhibited similar mean levels of aggressive behaviors frequently had meaningfully different patterns of psychological precursors, such that some children were aggressive when threatened by peers but not when confronted by authoritative adults, while others showed the opposite pattern (Wright \& Mischel, 1987). However, the methods used and available at that time were not tests of probabilistic relationships between context and behavior as hypothesized by 
conditional approaches. These studies also highlight a second limitation, conditional approaches focused solely on the influence of context on behavior, rather than how behavior may evoke different contexts $(p(\mathrm{C} \mid \mathrm{B}))$. Thus, it is arguably important to investigate how $p(\mathrm{~B} \mid \mathrm{C})$ and $p(\mathrm{C} \mid \mathrm{B})$ vary across time and people in order to understand personality dynamically. In sum, although the initial studies of if...then contingencies utilized paradigm-shifting data collection methods (extensive repeated assessments by observers at a summer camp), the statistical models of the time were not able to probabilistically model the contingencies, a question we will return to in the section on the future of personality measurement and modeling.

\section{A Cognitive Affective Personality System. Mischel and Shoda’s (1995) Cognitive} Affective Processing System expanded on conditional approaches to personality by focusing on the psychological features of contexts (e.g. felt threatened), rather than the objective features (e.g. social situation with peers). These psychological features activate what they term cognitiveaffective units (CAU's), which include encodings, expectancies and beliefs, affect, goals and values, and competencies. Different cognitive-affective units are not independent but dynamically influence and interact with one another.

The CAPS model has several distinguishing features. First, by incorporating both psychological features of situations and cognitive-affective units into the prediction of behavioral outputs, the CAPS model accounts for different precursors of the same behavior. Second, the CAPS model explicitly accounts for different sources of variability, some of which is captured by variability in situations that influence variability in cognitive affective processing units that bi-directionally influence one another. Third, the CAPS model includes a feedback loop with behavior predicting the contexts an individual experiences. In other words, it aims to capture the missing $p(\mathrm{C} \mid \mathrm{B})$ from conditional approaches. Fourth, the CAPS model provides an alternative 
way to conceptualize of the idiographic structure of personality. Rather than using a P-technique factor model to reduce within-person variability to a set of relative unique traits, one could attempt to model the dynamic relationships among those indicators. P-technique and related methodologies do not have the capability to account for changing dynamics between situation and cognition when, for example, affect differs.

Fifth, the CAPS model explicitly introduces behavior into the model of personality. In other words, rather than examining variability in composites of trait manifestations over time or contexts, the CAPS model directly addresses how situation features and relationships among cognitive affective units influence directly observable behavioral outputs. Finally, the CAPS model highlights different levels of individual differences within a person. People can differ in the psychological features of situations, how those features relate to and activate cognitive affective units, and how those cognitive affective units influence behavioral outputs. Because of the multitude of ways that individuals can and do differ and the cascading effects of those differences at different levels, it ultimately makes little sense to build a science of personality based at the level of a group or population. Instead, the CAPS model highlights the importance of understanding and modeling a person in their own unique (idiographic) complexity and outlines locations to search for the key variables that will help to elucidate those differences. In other words, the CAPS model's levels of individual differences highlight the need to consider personality idiographically. The underlying structure of individuals' personalities are likely to be nearly incomparable across people.

Given these vast number of individual differences at the person level, the CAPS model has important disadvantages that have prevented systematic tests of its implementation and predictions. Some disadvantages are practical. To investigate the relationships among cognitive 
affective units requires intensive time series data (with many occasions (T) and variables (X) from Cattell's data box). Moreover, how to define those cognitive-affective units and situations as well as how often to measure them remain substantive questions (although see Rauthmann et al., 2014; Parrigon, Woo, Tay, \& Wang, 2017, for exceptions). Moreover, even once data are collected, it does not provide a clear method for actually testing or modeling its premises. It is also unclear how to adequately capture fine-grained measures, like encoding processes, in the naturalistic settings fundamental to personality assessment and modeling. Finally, the time scale on which the CAPS model operates is unclear, which makes it difficult to impossible to capture the probability by which the system moves among different states. Thus, the CAPS model is ultimately an important theoretical tool for thinking about personality and individual differences, but the complexity and vagueness of its parameters still renders it mostly untestable.

Social cognitive approaches represent important advances in the study of personality broadly and personality dynamics more narrowly. The Person-Situation Debate prompted personality psychologists to focus in on the search for cross-situational consistency and temporal stability where cross-situational inconsistency was seen as measurement error. But social cognitive approaches shifted the focus, making (in)consistency (within-person variability) a key outcome variable to be explained. Moreover, it drew attention to the fact that variability in observed manifestations of personality, patterns of which were often represented as profiles of responses in different contexts, was an individual differences characteristic worthy of systematic study.

\section{Recent Thinking on Dynamics}

Within-Person Variability 
Following the rise of the Big Five as the dominant between-person structure of personality traits (Golberg 1981, Costa \& McCrae 1985) in the 1980s, personality research throughout the end of the $20^{\text {th }}$ century seemed to largely put aside the question of crosssituational consistency in favor of better understanding the Big Five structure, its robustness across time and cultures, and what it predicted. However, the beginning of the $21^{\text {st }}$ century saw questions of consistency and stability reappear under a new name - within-person variability.

For example, Fleeson (2001) extended Zuckerman's (1979), Buss \& Craik’s (1980), and Epstein's (1983a) contention that personality traits were aggregates of states. Although Fleeson (2001) concurred that the means of distributions of states reflect traits, he further argued that states and traits could be linked by investigating other parameters of distributions of states. ${ }^{1}$ The peak of the distribution represented the average state (or trait) levels of a specific characteristic. But density distributions also have other characteristics, such as dispersion (e.g., range and standard deviation of states), skew, and kurtosis, all of which provide information above and beyond mean levels alone. Although the idea and importance of variability were far from a new idea, Fleeson's (2001) density distribution perspective moved variability from being useful for determining stable estimates of traits to being a focal point itself.

Work on linking state and trait assessments through density distributions was supported by new data collection techniques. Indeed, arguably no method was more important for advancing the study of within-person variability than the rise of the Experience Sampling Method (ESM; Larson \& Csikszentmihalyi, 1983). ESM data, which can be called multivariate

\footnotetext{
${ }^{1}$ The idea that mean-levels and variability of personality were connected was not new. Cattell (1957) wrote extensively on the topic of variability and the need to assess the relationship between personality "levels" and variability, but because there were several structural theories of personality (including Cattell's 16 factor solution; Cattell, Eber, \& Tatsuoka, 1970), none of which were dominant or involved the large-scale data collection of states that the Big Five have garnered in the last 20 years, such questions were almost completely unexplored.
} 
time series data or intensive repeated measures, among other names, include a set of variables from a single individual multiple times within or across days or weeks. While data such as these have been collected since the 1940s or earlier (e.g. Cattell, 1947), there was no coherent framework on how to assess personality, and such data were not routinely collected until the introduction of electronic assistants that help "ping" participants throughout the day, which has become increasingly easy as smartphone access becomes more ubiquitous worldwide.

Through using these and other techniques, such as the Electronically Activated Recorder (EAR; Mehl \& Robins, 2012), personality scientists have been able to demonstrate that between person traits do correspond to averages of states (Fleeson \& Gallagher, 2009). Moreover, work on person-situation transactions has also witnessed a resurgence (e.g., Breil et al., 2019; Sherman, Rauthmann, Brown, Serfass, \& Jones, 2015). However, despite this resurgence, research on within-person variability has largely focused on static estimates of variability of single states within-person over time, rather than how states may predict each other (and even themselves) within and across time - that is, within-person variability is not a dynamic model or technique for understanding personality. Below, we turn to tools currently available to personality scientists that allow them to test dynamic questions.

\section{The Future of Dynamics}

"Novel and somewhat daring methods will be required" (Allport, 1937, p. 20).

The $20^{\text {th }}$ century saw the introduction of personality psychology as well as its refinement. But Allport, Cattell, and others posed a number of key questions that could not be addressed using data collection and statistical techniques available at the time. Some of these questions (e.g. the correspondence between P-technique and R-technique factor analyses of within- and between-person data) were partially addressed, while others (e.g. the processes and dynamics of 
personality) remain under-addressed or completely unaddressed. In this section, we introduce how the recent surge in interest in network techniques in psychology and other fields of science coupled with recent developments in time series modeling allow personality scientists to finally address many of the un(der)addressed questions concerning personality dynamics.

\section{A Dynamic Systems Theory of Personality}

Despite the promises of using ESM and modeling techniques like multilevel models to investigate "within-person processes," several researchers have laid out evidence suggesting that using between-person models, like factor analysis and MLM, to investigate within-person processes, is often misleading and does not allow for strong (causal) conclusions (Borsboom, Mellenbergh, \& Van Heerden, 2003; Molenaar, 2004; Fisher, Medaglia, \& Jeronimus, 2018). However, establishing the connection between the two sciences of personality (idiographic and nomothetic) is key if we (1) wish to make inferences about one level using the other or (2) want to determine the best level of analysis for a specific question. Both Allport $(1937 ; 1961)$ and Cattell $(1947 ; 1957)$ were careful to point out that there was little reason to think that these two approaches would yield the same results when conducting P- or R-technique factor analysis. But whether this is ever the case is both a theoretical and empirical question that went almost completely unanswered until the $21^{\text {st }}$ century. Evidence of the lack of correspondence between between- and within-person personality structure has come in form of mathematical (Borkenau \& Ostendorpf, 1998; Molenaar, 2004), theoretical (Borsboom et al., 2003), and empirical (Fisher et al., 2018) evidence.

Mathematically, if within-and between-person processes were equivalent, they would be ergodic (Molenaar, 2004). In psychology, this would mean that there would be equivalence between P-technique factor analyses of multivariate time series data (X x T, fixing $\mathrm{P})$ and $\mathrm{R}$ - 
technique factor analyses of multivariate data $(\mathrm{X} \times \mathrm{P}$, fixing $\mathrm{T})$. Since manifest variables are generally Gaussian processes, the requirements for demonstrating whether between and withinperson processes are equivalent is quite straightforward, but multivariate time series of psychological indicators do not meet them. Indeed, in a recent demonstration, Fisher et al. (2018) investigated the equivalence of within-and between-person means and standard deviations, finding that the distributions were quite different, which indicates that the time series are nonergodic and individual-level estimates cannot be made from between-person estimates. ${ }^{2}$ Such an observation should not be taken lightly, as it suggests that inferences based on between-person models may be misleading at best and wholly incorrect at worst, which seriously threatens the scientific process.

Theoretically, critical assumptions of the factor model underlying the derivation of nomothetic (common) traits in personality make it unlikely that nomothetic structures can be used to understand individual-level dynamics. Models of the Big Five were originally extracted using exploratory factor analysis. Three important assumptions of this so-called reflective model (or common effect model; see Figure 2a) are that (1) the indicators of these traits are assumed to be interchangeable, (2) their errors are independent after conditioning on the latent variable, and (3) the latent trait causes variability in the indicators. The use of the reflective model in personality has been criticized for violating each of those three assumptions (e.g. Cramer et al., 2012). Although the independence and interchangeability of indicators assumptions can be somewhat bypassed by fitting confirmatory factor models that relax these assumptions (e.g. Hopwood \& Donnellan, 2010), the question of the causal nature of latent variables remains.

\footnotetext{
${ }^{2}$ For a more thorough discussion, we refer reader to read Borsboom et al. (2003), Molenaar (2004), and Fisher et al. (2018) in detail as they make important points on what considerations and preliminary tests should be conducted on multivariate time series data before conducting descriptive and inferential tests.
} 
However, there are other models that are mathematically equivalent to the common reflective model that relax all of these assumptions (Kruis \& Maris, 2016). However, despite their mathematical equivalence, each of the models proposes a different theoretical explanation for the observed associations. Thus, the choice of the model may not greatly affect model fit, but it has critical implications for a theory of personality.

Two other models that are mathematically equivalent to the reflective model - the formative model (or common cause model) and a network model - are shown in Figure 2b-c. In a formative model, a latent variable is regressed on its indicators. A classic example of this is socioeconomic status, where indicators like education, household income, and location are indicators of the construct SES. However, there is no assumption that education, income, or location cause SES. In personality, in other words, observable manifestations of Extraversion, like being talkative, are not caused by some Extraversion trait that a person has. Rather, their position on the latent construct Extraversion is a function of their tendency to be talkative, as well as a number of other indicators. However, although the formative model relaxes assumptions of the reflective model that often do not hold (perhaps especially the independence of errors), it fails to provide a satisfying explanation for why latent traits emerge at all.

The network model, though, not only relaxes reflective model assumptions but also suggests explanations for why latent trait dimensions emerge. Based in dynamic systems theory, a network model asserts that latent traits emerge as emergent properties of interactions among a set of indicators, rather than simply as how levels of a variable tend to discriminate among individuals. 
Reflective

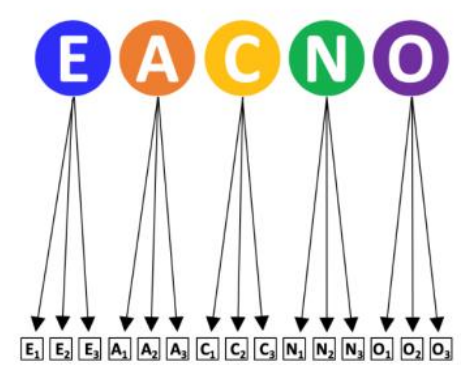

Formative

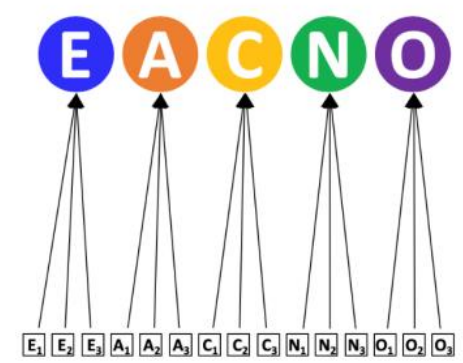

Network

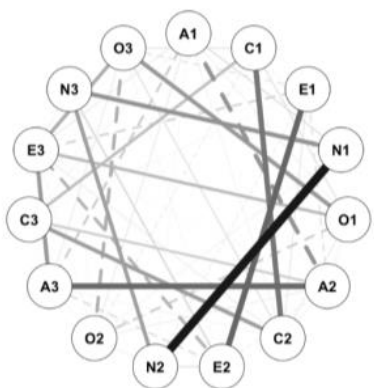

Figure 2. Simplified visualizations of three mathematically equivalent models of the same indicators. 2a shows a Reflective model, which is most often used in psychology, in which the indicators are regressed on the latent variable. $2 \mathrm{~b}$ shows a Formative model, which is most often used in other social sciences, in which the latent variable is regressed on the indicators, relaxing key assumptions of the Reflective model. 1c shows a network model, which is becoming more used across scientific disciplines, in which pairwise interactions among all indicators are assumed to have emergent properties.

Empirically, how strong the mismatch between within- and between-person models is

likely due to differences in materials, procedure, and sampling. Across studies that have examined the question, the mismatch exists (e.g. Beck \& Jackson, 2020b; Borkenau \& Ostendorpf, 1998; Borsboom et al., 2003; Fisher et al., 2018; Molenaar, 2004), which, at best indicates that inferences based on between-person models in psychology will be imprecise, and at worst could completely undercut the validity of key theories and models (Fisher at al., 2018). Although Allport (1937) both anticipated these concerns in the early $20^{\text {th }}$ century and advocated for within-person studies of personality as a solution, it has taken nearly a century for these concerns to return to the fore in personality. Now, the Allportian call for more idiographic approaches to personality assessment and theory appears prescient and offers a pathway forward.

If mismatch between idiographic and nomothetic models is strong, as it often is in psychology, then psychologists must turn their attention back to testing idiographic questions posed by Allport and others almost a century ago. Recently, for example, Beck and Jackson (2020b) examined the congruence between idiographic and between-person personality structure using well-known (if not oft applied) techniques, like P-factor analysis, as well as newer models 
that account for timing (lagged) effects. In total, they examined idiographic — between-person congruence for six classes of models (e.g. cross-lagged autoregressions and unified SEM, see below). Across each method, they found little congruence between the between-person reference structure and idiographic structures, with some people showing strong congruence but many showing weak congruence at best. In short, the personality structure of an individual does not necessarily map on to the current taxonomies of personality structure (e.g., HEXACO; Big Five). People are unique in how their personality is organized, with some components being important for some people but not others.

Although further work is needed to better understand the correspondence between withinand between-person models of personality structure and how variability can be leveraged to improve our understanding, this study represents the most comprehensive study to date examining methods for assessing congruence. The lack of evidence for such congruence is striking and further highlights the need for devoting more attention to idiographic assessment and modeling. If personality traits are causally influencing distal outcomes decades down the road, then it is necessary to identify the components that are the influencers. The findings from Beck \& Jackson (2020b) indicate it is incorrect to label such terms like Conscientiousness as these distal influences (e.g., Hill \& Jackson, 2018) given that Conscientiousness may not "exist" for some individuals.

\section{Network Tools}

Network approaches have recently garnered considerable attention, with some touting the great advantages these models offer (Beck \& Jackson 2020b; Borsboom \& Cramer, 2013;

Cramer et al., 2012), and others some of the downfalls (Forbes et al., 2017; 2019; Bos et al., 2017; although see Borsboom et al., 2017 for a contrasting opinion), particularly in cross- 
sectional research that does not utilize time series designs. Networks highlight relationships among indicators, visually and quantitatively representing complex relationships between indicators that reveal both direct and indirect relationships between them. Moreover, idiographic networks are better suited to answering questions of intraindividual personality processes that are not easily testable within factor models (see Beck \& Jackson, 2017, 2020b,c). Unfortunately, only a few studies have used network approaches to examine personality (e.g. Beck \& Jackson, 2020b; Wright et al., 2019), and of those that have, only one has used networks to conduct idiographic assessments of personality and looked at networks of time series data longitudinally (across two years; Beck \& Jackson, 2020b). Despite this, the dearth of research on this topic means it remains unclear to what extent networks models can be used with time series personality data and to what extent they can be used for idiographic assessment.

Importantly, what makes a network model is not an estimation procedure but the methods that can be applied to data or results structured as matrices. ${ }^{3}$ Essentially, the rows and columns indicate the nodes (or variables) under investigation while the cells of the matrices represent the edges (or relationships) among the nodes. The simplest procedure is zero-order correlations among the variables $(\mathrm{X})$ dimension across the time $(\mathrm{T})$ dimension for each person individually (see Figure 3a). Called "association networks," these are the correlation matrices that Ptechnique factor analysis attempts to reduce. In other words, rather than looking at the relationships among unique variances among all indicators, such models examine all overlapping variance among indicators. Figure 3 shows a visual representation of the steps from raw data to representing within-person correlations as a network.

\footnotetext{
3 Throughout this paper, we will sometimes use the term "network model" to refer to VAR models and other time series models whose results can be represented in matrix form. Moreover, we will use the term "edges" to refer to coefficients from the VAR and other time series models.
} 


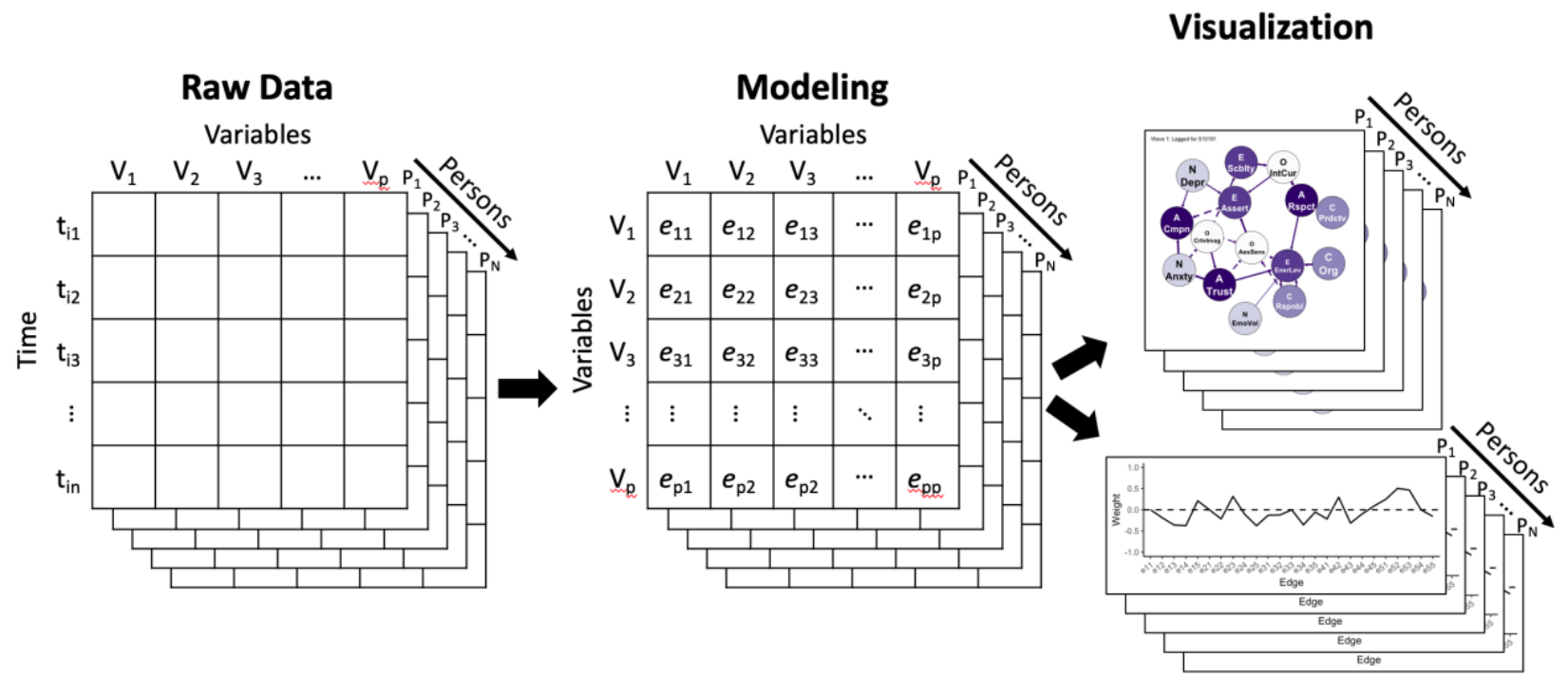

Figure 3. A simplified analytic procedure for using network tools on idiographic time series data from raw data (3a) to modeling relationships among variables $\left(\mathrm{V}_{1}\right.$ to $\mathrm{V}_{\mathrm{p}}$ ) and formatting them as a matrix (3b) to visually displaying them as a network or profile of relationships (3c).

However, because there is likely to be strong overlapping variance among indicators, it may also be important to examine the unique relationships among the indicators using partial correlations or regression. In such cases, the possibility of over-controlling or overfitting the model increases (assuming the number of observations remains constant). Recently, there have been a number of proposed models for examining such complex models without overfitting. New techniques for the basic lagged, or vector autoregressive (VAR) model (e.g. Bringmann et al., 2016; Epskamp, Waldorp, Mõttus, \& Borsboom, 2018; Gates \& Molenaar, 2012, Wild et al., 2010), have been proposed and implemented (in a limited manner) to account for (1)

bidirectional relationships between lagged predictors, (2) additive relationships among lagged predictors, and (3) the structure of these relationships (Beck \& Jackson, 2020b). Cross-lagged VAR models have several advantages. First, most account both for within-(contemporaneous) and across- (lagged) time relationships. Second, by including larger set of predictors and using pruning techniques to prevent multicollinearity (e.g. graphical LASSO; Friedman, Hastie, \& Tibshirani, 2008), they capture the unique relationships among diverse phenomena that influence 
manifestations of personality. Third, and most simply, they offer a method for testing complex sets of relationships that are a hallmark of many key models of personality (Allport, 1937; Cervone, 2005; Mischel \& Shoda, 1995). Such relationships are complex not only in that they can include a large number of predictors but also in what those predictors are. For example, within such a framework, one can include state measures of both personality and situations (c.f. Beck \& Jackson, 2017).

Another way of conceptualizing cross-lagged VAR models is in the language of conditional frameworks of personality (Wright \& Mischel, 1987). Lagged relationships should better indicate if ...then contingent relationships, while contemporaneous associations capture while relationships. In other words, cross-lagged VAR models allow personality researchers to test for conditional associations that characterize the study of person $\mathrm{x}$ situation interactions, while explicitly modeling those in a framework that also controls for the influence of other psychological variables. As a result, the relations among situations and state variables capture the conditional relationships between personality states and situation variables over time. This has two main advantages. First, conditional situational state relationships steps beyond traditional approaches to looking at person-situation transactions that look at symmetric (i.e. not accounting for time) relationships between them. In other words, there may be asymmetric relationships, such that some situations are better predictions of behaviors than vice versa. Second, asymmetric relationships correct for a previous over-emphasis on examining $p(\mathrm{~B} \mid \mathrm{C})$, omitting the investigation of $p(\mathrm{~B} \mid \mathrm{C})$ and $p(\mathrm{C} \mid \mathrm{B})$. That is, traditional approaches do not examine how contexts influence personality manifestations, as well as how those manifestations influence the context, which are easily implemented in cross-lagged VAR models. 
But association networks (zero-order correlations) and cross-lagged VAR models are not unique in generating estimates of these relationships. Indeed, the most important question when considering whether to represent and understand data or models from a network perspective, concerns the definitions of the nodes and edges (Beck \& Jackson, 2019; Piccirillo, Beck, \& Rodebaugh, 2019) - that is what are the indicators (nodes) and the relationships among them (edges). For example, should the lowest-level measurement unit be items, or should the items be composited into higher-order constructs? Perhaps even more important than the definition of the nodes is the definition of the edges, which can represent adjacency (or co-occurrences), correlations, partial correlations, frequencies, individual differences, and more (c.f. Beck \& Jackson, 2020b; Wood, Spain, \& Harms, 2020). Moreover, the edges can represent different time scales. Contemporaneous (also known as lag 0 or contemporaneous; while relationships) relationships estimate probabilistic within-person same time point relationships - that is, the tendency for two manifestations of personality to occur at the same time - and can be thought of as "while" relationships. Lagged and cross-lagged relationships (also known as lag 1 or simply "lagged"; if...then contingent relationships), in contrast, estimate probabilistic within-person, cross-time point (or cross-lagged) relationships - that is, the tendency for two manifestations of personality to follow the other across measurement occasions - and can be thought of as if...then relationships, partialling out associations with other indicators (e.g. Wright \& Mischel, 1987).

As we will demonstrate in the following sections, using networks to represent the withinperson relationships among variables over time idiographically can inform the study of personality structure and processes in ways that address questions raised by Allport, Cattell, and others. To do so, we will use example data and participants from an ESM study of personality and relationships and use lagged partial correlations from a graphical VAR model. However, 
because our goal in the following section is to highlight how network tools further the study of idiographic personality, the interpretative and visualization procedures apply broadly to other ways of defining nodes and edges as well, which we will discuss below in the section on (re)defining personality structure and dynamics.

Personality structure. Most simply, by providing an intuitive visualization of the relationships among indicators, network techniques provide an easy tool for visualizing structural differences in personality. Moreover, when used with time series data, network visualizations can be used to examine differences in the structure of individuals' personalities, rather than just levels of traits. For example, taking a sample of individuals from the Personality and Interpersonal Roles Study (PAIRS; see Beck \& Jackson, 2020b for more details), we can construct idiographic graphical VAR models of their contemporaneous and lagged relationships among Big Five indicators as well as examples of each of the five classes of CAU's from the CAPS model (encodings (social power), expectancies and beliefs (free), affect (positive and negative emotion), goals and values (academic motivation), and competencies (willpower)).

After constructing networks for each participant using a time series technique, like graphical VAR models that sequentially estimate lagged and contemporaneous relationships, we can examine the similarity in the structure of each individual's personality to the "common" nomothetic structure of those relationships, and their similarity to other participants. Figure 4 shows a sample of six participants' contemporaneous networks. As is clear from the figure, participants had different "while" relationships among personality manifestations and CAU's within time points. For example, some had many strong connections among edges (e.g., S5567) whereas others had relatively fewer associations between personality manifestations (e.g., S79375). 

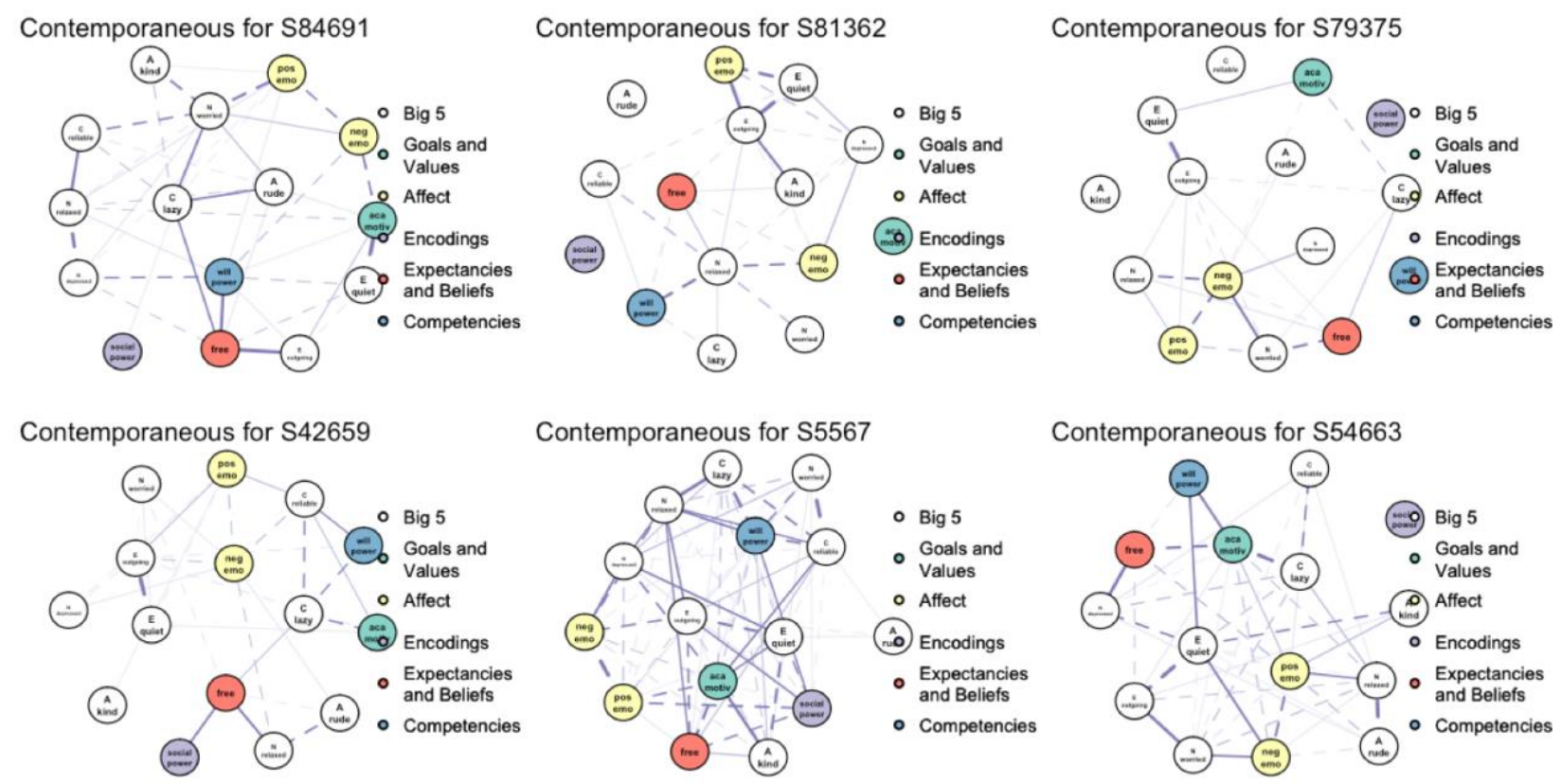

Figure 4. Sample network visualizations of 6 participants Experience Sampling Method (ESM) data of Big Five states and sample Cognitive Affective Units (CAU's). Nodes (circles) represent each of the indicator variables, the colors of the nodes represent the type of state (Big Five or $\mathrm{CAU}$ ), and the edges (lines connecting the nodes) visually depict the partial correlations among the variables.

To see just how different participants are from other participants in the sample, we can examine pairwise profile correlations between the while relationships for all possible combinations of participants. Figure 5 presents the distributions of profile correlations examining congruence between the six sample participants and all other participants in the full sample. As is clear in the figure, participants differed both in the average level of congruence they had with other participants as well as the overall variability of those distributions. Moreover, although there is non-trivial convergence between most of the participants and other participants, on average, the estimates tend to be far from ceiling, indicating between-person differences in idiographic personality structure across participants. 


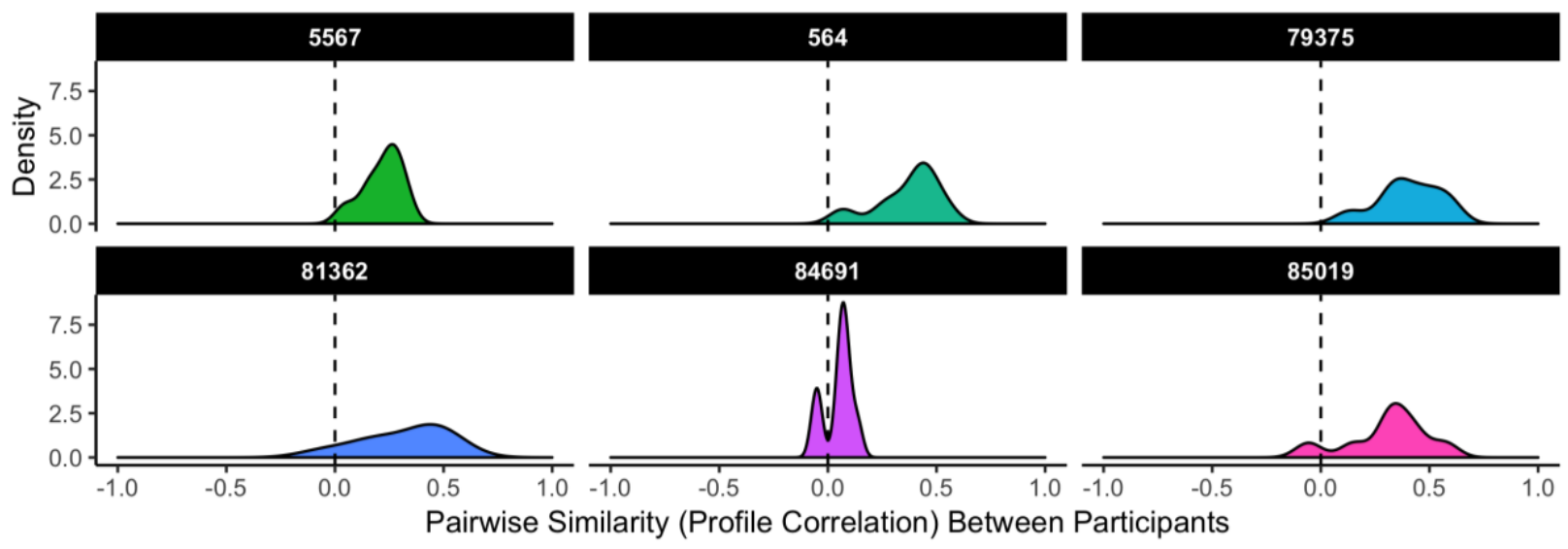

Figure 5. Density distributions of pairwise congruence between 6 sample participants and all other participants (including participants not shown). The $\mathrm{X}$-axis represents correlations between a target participant and another participant in the sample (range -1 to 1), the Y-axis represents the density of that relationship, and different panels represent different participants. The dashed line at 0 indicates where there is basically no relationship between a target participant and all other participants.

Personality processes. When time series data, such as those collected using ESM, are used, networks can also be used to understand the processes that underlie personality.

Frameworks for understanding personality processes, like the CAPS model - which argues that behavior is an emergent property of the influence of situation construals on the relationship among unique sets of Cognitive Affective Units ${ }^{4}$ (CAU's) - can be integrated with network techniques and time series models to understand personality processes.

For example, in the simplest case, if personality at the individual-level is assumed to be relationships within (contemporaneous) and across (lagged) time of the indicators of Big Five personality traits, then these can be easily modeled as partial correlations among the indicators (c.f. Beck \& Jackson, 2017, 2020b). Then, to understand how the underlying CAPS framework processes influence not just the level of specific manifestations, as has typically been studied, but also the relationships among those manifestations, models containing different CAPS framework components can be compared to models containing only personality manifestations (as opposed 
to constructing models containing all CAU's as shown in Figures 2 and 3). For example, taking Participant 1 in Figure 3 as the reference point, we can construct a network of just their Big Five personality manifestations and add an example of each of the CAPS CAU's individually and examine the structural change (Encodings (social power), expectancies and beliefs (free), affect (positive emotion), goals and values (academic motivation), and competencies (willpower)).

For simplicity, the differences in structure can more easily be seen if the profile of edge weights is compared across networks, as is shown in Figure 6 Points in the profile where the strength of relationships vary depending on whether CAU's are modeled suggest that those processes influence the relationships among personality manifestations. For this participant, it is clear that the goal / value of academic motivation most impacted the if...then network structure of their personality. Relative to when the other CAU's were accounted for, there are relatively sharp changes in relationships among the indicators. Most notably, these differences largely moved the network toward showing stronger contingent patterns among the indicators. For example, when academic motivation is higher, the participant showed positive relationships between current kindness, laziness, and outgoingness and future quietness that were not seen when academic motivation was lower or when other tested CAU's were higher. Thus, even if the participant is currently feeling outgoing or lazy, academic motivation can push them toward quiet pursuits, perhaps like studying. Thus, accounting for academic motivation helps to better understand how personality functions over time. Without accounting for CAU's, like academic motivation, there may be cases, like the one above, where "true" relationships appear null (or vice versa). 


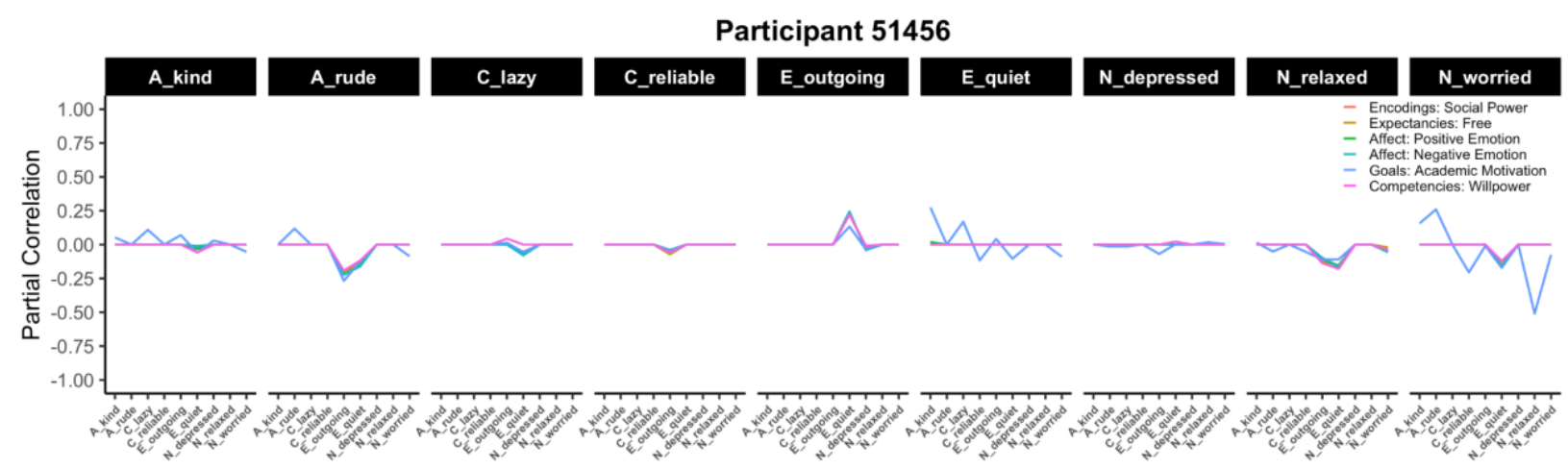

Figure 6. A profile of time series models of Big Five states accounting for different Cognitive Affective Units (CAU's) - Encodings (social power), expectancies and beliefs (free), affect (positive and negative emotion), goals and values (academic motivation), and competencies (willpower). The $\mathrm{X}$-axis displays current time-point Big Five states, different panels present next time point $(t+1)$ Big Five states, the Y-axis, is the average relationship between current and future Big Five states, and different lines indicate which CAU the model controlled for.

Deviations across lines suggest that the CAU impacted the relationship among present and future Big Five states.

Redefining Processes and Dynamics

As we demonstrated above, using network techniques with time series models of personality data provides new ways of thinking about idiographic personality structure as well as the processes that underlie the manifestation of personality in everyday life. Below, we outline several promising alternatives beyond (1) simple lagged and contemporaneous relationships and (2) beyond zero-order correlations, partial correlations, and regularized regressions each of which are compatible with a basic network approach (i.e. producing matrices of relationships among indicators) as well as with dynamic systems theory more broadly. We also discuss some of the major challenges to understanding psychological dynamics, particularly as they relate to the treatment of time.

Personality as a dynamic system: It's about time. In 1957, Cattell noted the importance of incorporating time effects into models of personality. Similar to his discussion of periodicity and cycles in psychological states, accounting for different time effects is important for creating reliable models from which conclusions can be drawn. Indeed, Cattell (1957) wrote that "the task 
of research is first to establish statistically and experimentally the nature of the rhythms and then to trace them to internal physiological or external environmental sources, or both" (p. 610).

More colloquially, timing is an important dimension in understanding personality. When we consider the theories we have about the personalities of others, the frequency of, duration of, and change in experiences all play an important role in the ways in which we understand them. Colloquial phrases like "[They] are so often tired" (frequency), "[They] can get stuck in an anxious state for days" (duration), and "[They] can turn on a dime" (change) all highlight how time is an explicit part of how we define the personalities of others.

Thus, the methods appropriate for building personality theory require that the way that manifestations unfold over time, not just their momentary or aggregated levels, are incorporated. Unfortunately, the methods reviewed thus far, including zero-order and partial correlations represented as networks, require equal spacing between measurement occasions, which is difficult to impossible to collect in practice because of late or missing responses. Thus, alternative methods are needed to more flexibly account for time. Below, we detail one such method - change as outcome models based in differential equation modeling. For other approaches, see [Note to editors: would like to add references to other chapters in this volume here].

The speed of psychological processes. To Allport, personality traits were a "form of readiness for response" (Allport, 1937, p. 293), which could indicate a general propensity for a response (similar to an if...then contingencies) as well as the more continuous probabilistic estimate of the rate at which a response is arrived. Thus, in line with social cognitive and conditional perspectives, considering personality as a readiness for response argues that patterns 
of changes in these processes capture personality itself, not simply within-person variability or error variance that one wants to pull out of a model.

However, studying how personality changes over time is not well-defined. If readiness for response is characterized by action tendencies, these can be modeled continuously as rates of change, or velocity (Revelle \& Condon, 2015). Between-person differences in velocity, to which a bulk of the personality literature has been devoted to, capture the frequencies, latencies, or persistence, which are not equivalent to the within-person rates of change (Revelle \& Condon, 2015). Although analytic techniques that capture velocity, like differential equation models that describe the relationship between the level of variable and its derivatives with respect to time (Boker, Neale, \& Rausch, 2004), personality has not been modeled as a set of differential equations where both distance (e.g. frequency) and velocity are captured, with a few notable exceptions (c.f. Revelle \& Condon, 2015).

An important step in understanding how personality operates in everyday life and why personality predicts a number of consequential life outcomes is to test whether personality, as measured in everyday life, can be used to estimate "readiness for response" as the velocity (first derivative with respect to time) and whether the velocity predicts similar life outcomes as levels of personality do. If velocity provides unique information above and beyond level, this should prompt personality psychologists to search for techniques to recover velocity from level and whether better techniques for assessing velocity, perhaps even nomothetically (e.g. incorporating time effects into nomothetic personality items), should be an important and active area of investigation.

\section{Systems: It's about equilibria.}


However, capturing velocity alone does not capture personality as a dynamic system. Instead, dynamical systems theory posits that "the higher order interactions ... constitute emergent patterning where multiple variables and contexts are pushing and pulling one another in a coordinated dance over time. This dance generates temporal patterning that is descriptive of the overall system, and these patterns can be depicted through models of change" (Butner et al., 2014 , p. 2). In other words, velocity, which changes over time, has direct implications for the frequency and duration of different psychological states (Revelle \& Condon, 2015). Because velocity is the first derivative of distance with respect to time and its integration estimates the average distance, the integrated velocity of a psychological process is its average level over time, which suggests why the average of density distributions of personality states correlates strongly with trait levels.

The importance of the relationship between velocity (momentary change) and level is more easily understood visually. Figure 7A presents the time series of a single variable $\mathrm{X}_{1}$ with respect to time for both its level (top; $\left.\mathrm{x}_{t}\right)$ and change (bottom; $\left(\mathrm{x}_{t}-\mathrm{x}_{t-1}\right) /(t-t-1)$. Importantly, by visualizing a time series of change, it becomes clear that the same methods that have been applied to raw times series (e.g. within-person standard deviations, multilevel models, etc.) can also be applied to the time series of change. This is visually depicted as the histograms of both level and change in Figure 7B. 

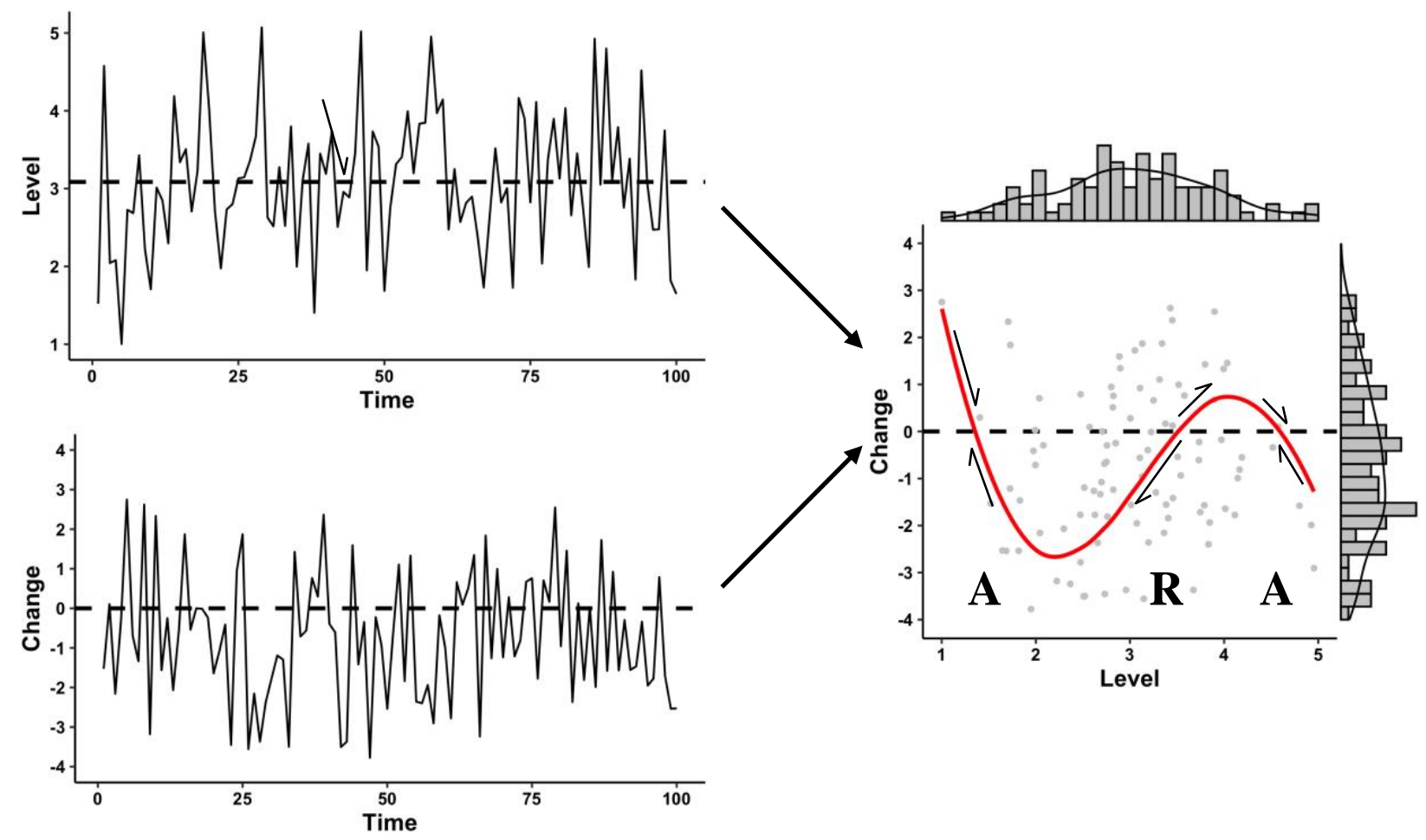

Figure 7. Time series of both level (A top) and change in level (A bottom) as well as the relationship between level and change (B; i.e. change as outcome). Points that cross the $\mathrm{Y}$-axis are equilibria in change as outcome models that can be either attractors (A) or repellers (R). Marginal density distributions represent the observed distribution of level $(\mathrm{X})$ and change $(\mathrm{Y})$.

Increasingly, there have been calls to consider personality as a system in which aggregate trait levels capture equilibria, or set points, in the system (e.g., Cramer et al., 2012; Sosnowska, Kuppens, DeFruyt, \& Hofmans, 2019). Systems have equilibria points that are determined by relationships between level and change among system components. Equilibria govern the push and pull of system components, or how the state of system at a given point in time predicts the likely direction in which it will move. In a dynamical system, equilibria are points at which the system is unlikely to move without perturbation - that is, when change is zero - similar to set points often talked about in the well-being literature (e.g., Diener, Lucas, \& Scollon, 2009). Thus, by plotting the relationship between level and change as in Figure 7B, the levels at which 
change is unlikely (i.e. equilibria) can be detected. In Figure 7B, there are three equilibria because there are three points at which change would be expected to be zero.

The study of systems is concerned with understanding how much and quickly a system is likely to change given its current state (i.e. levels), not where the system is at observed time $t$ (hence level and not time on the x-axis of Figure 7B). When perturbed, systems will tend to move toward equilibria. The direction and speed at which they do is determined by the relationship between level and change. In Figure 7B, this is the local (pointwise) slope of the line. However, the local slope is a function of the level of a process, not a specific moment in time. Thus, by plotting level and change from the times series in Figure 7A against each other in Figure 7B, the time dimension is "hidden" or implied rather than expressly shown. Given the level of a variable, we can estimate of how much change we expect per unit of time, on average.

Equilibria can be of different kinds. Sometimes, the state of the system will push it toward a specific equilibrium (i.e. an attractor; see points labeled "A" in Figure 7B), while others will push the state of the system away (a repeller; see point labeled " $R$ " in Figure 7B), which is critical if there is more than one state of equilibrium. The slope of the line leading up to an equilibria point determines its strength. Imagine, for example, that Figure 7B represents someone who scores low in the nomothetic personality trait Emotional Stability and frequently reported being on the high or low end of state anxiety in an ESM study. Although this person may sometimes experience moderate anxiety, given any small perturbation, they are likely to move toward either low or high anxiety - that is, they are more likely to move toward the extremes than the middle. The extremes of anxiety, in this case, are attractors, while moderate anxiety is a repeller (they tend not to stay at that value very long). In this way, attractors and repellers help to explain why emotionally unstable people experience shifts in their emotions. Moreover, they 
may help to explain individual differences in when this occurs and how much individuals are expected to change (c.f. Revelle \& Condon, 2015).

Furthermore, when these states are considered as coupled - that is, there is a feedback loop - then the relationship between level and change in both variables can be modeled as a topology. Figure 8 presents an analogous 2 -dimensional extension of the 1 -dimensional change as outcome model presented in Figure 7. In this case, Figure 8A presents the time series of the level and change of two variables $\left(\mathrm{X}_{1}\right.$ and $\left.\mathrm{X}_{2}\right)$. As is clear in the figure, there is a small difference in level in the two variables, with $\mathrm{X}_{1}$ having a higher mean (dashed black line) than $\mathrm{X}_{2}$ (dashed blue line). Rather than the bivariate relationship between level and change that was shown in Figure 7B, looking at these states as coupled results in a vector field, or topology, that presents how different simultaneous levels of the two states leads to changes in both states.
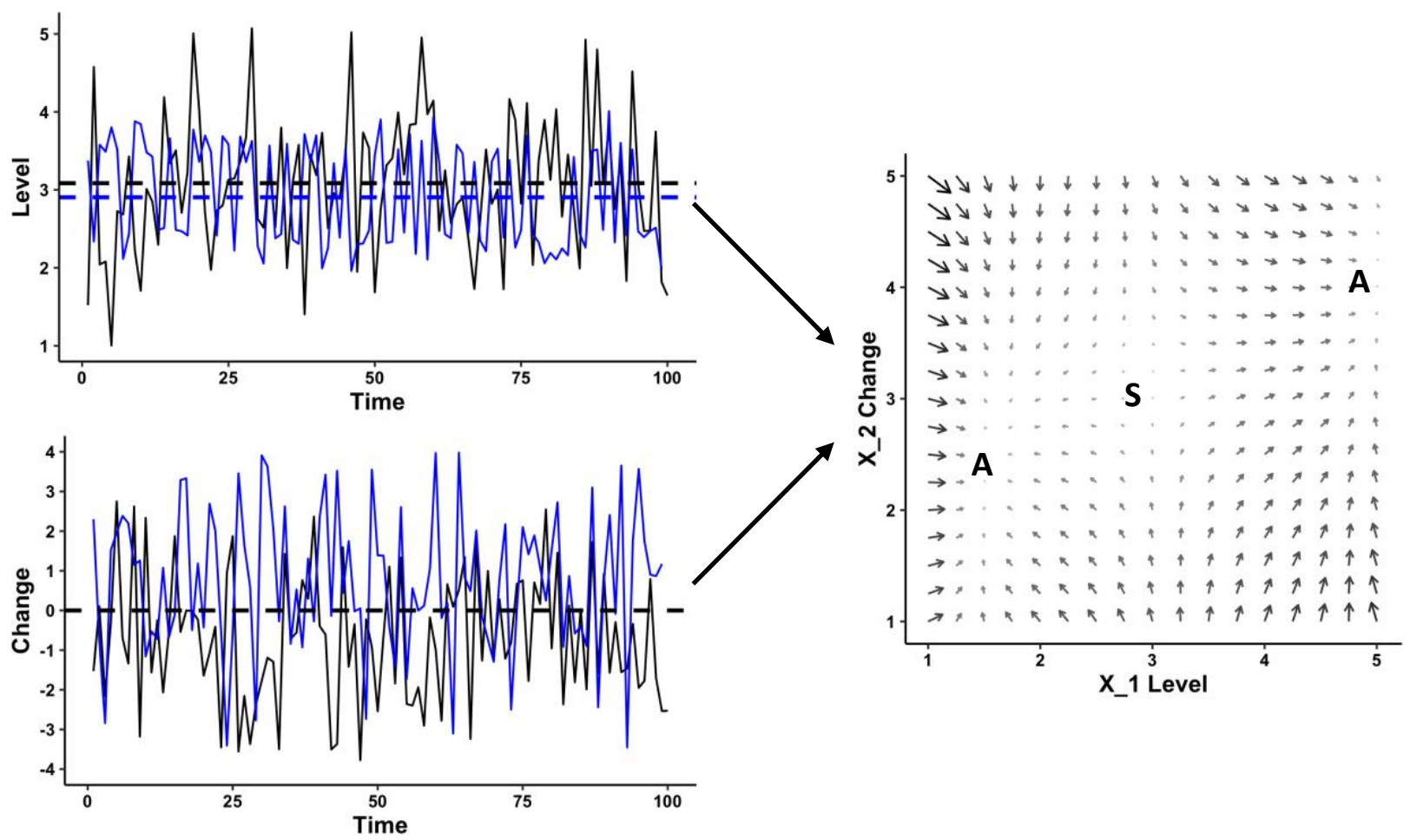

Figure 8. Two-dimensional change as outcome model of level and change of two coupled states, $\mathrm{X}_{1}$ (black) and $\mathrm{X}_{2}$ (blue). Time series of both level (8A) and change (8B) of both states are shown on the left of the column, while the relationships between level and change ( $8 \mathrm{C})$ is shown 
on the right as a topological map of vector fields. Equilibria are marked as " $\mathrm{A}$ " (attractor) and "S" (saddle).

Just as before, these coupled change as outcome models can incorporate non-linear relationships between level and change that can introduce new equilibria, demonstrate moderating relationships (i.e. product relationships that change whether equilibria are present), or change the location of equilibria. Indeed, in Figure 8, we modeled the cubic relationship between level and change for $\mathrm{X}_{1}$, and the linear relationship between level and change for $\mathrm{X}_{2}$, also accounting for the linear relationship between level and change for the other variable.

Because we are now accounting for two coupled states, there are new features that we can identify when looking at coupled change as outcome models using a topological map, such as the one shown in Figure 8B. These four core features are (1) fixed point attractors, (2) fixed point repellers, (3) saddles, and (4) limit cycles. Similar to how points that crossed the zero-change point in one-dimensional change as outcome models represented equilibria, points in which the arrows disappear (i.e. are in a topological valley), indicating zero change in both variables, capture fixed point attractors. In Figure 8B, there are two fixed point attractors at approximately 1.5 and 4.75 in level of $X_{1}$ and 1.5 and 1.25 in level of $X_{2}$. Because there are two attractors in Figure $8 \mathrm{~B}$, there must be at least one fixed point repeller or saddle. In this case, there is a saddle but no fixed point repeller. A fixed point repeller in a location in which arrows point away from each other and are analogous to a mountaintop in a topological map. Saddles, in contrast, are areas that separate the topological map into attractor regions. In Figure 8, there is a saddle at approximately 3.25 in level of $\mathrm{X}_{1}$ that extends across the full range of $\mathrm{X}_{2}$. When levels of $\mathrm{X}_{1}$ are near this boundary, it will pull $\mathrm{X}_{1}$ to one of the two attractors. Finally, a limit cycle, which is not present in Figure 8B, is essentially a point in the topological map where one would get trapped in a cycle. In other words, the arrows would be in a circle. 
Combinations of these four kinds of patterns can explain most patterning psychological phenomena. For example, variables with high autocorrelations (e.g. depression) may be captured by fixed point attractors, individuals who report many highs and lows likely have combinations of attractors at high and low levels with a fixed point repeller or saddle separating them, and individuals who stuck in variable but consistent cycles (e.g. fear of abandonment) may have limit cycles. In addition, combinations of these may explain why individuals are in a steady state (fixed point attractors) at lower levels of a variable but may be more unstable (but high) at a higher level (limit cycle) as well as unlikely to maintain moderate levels.

Although this method has great promise, to date, it has only been applied in a small number of cases (see Danvers, Wundrick, \& Mehl, 2020 for an empirical example using personality data). Given the appropriateness of this method for time series data, especially time series data with unequal measurement intervals, we hope that this illustrative review challenges psychological scientists to consider more dynamic modeling techniques in designing future studies.

\section{Conclusion}

In this paper, we charted the history of theoretical and empirical approaches to understanding personality as dynamic. Since its emergence as a discipline, personality has juggled a number of goals. First, it grappled with whether personality was a between or withinperson phenomena, as highlighted by early writing by Allport and Cattell, as well as later writings by Mischel. Second, it grappled with how personality relates to prediction - that is, whether personality should be thought of as global summaries that predict behaviors or whether the dynamic nature of personality should be more predictive of behaviors. 
We put forth a number of arguments that the path for integrating these questions across levels lies in conceiving of personality idiographically, according to a dynamic systems approach. Considering personality as a system can be most simply understood from the framework of recently popular network approaches in psychology. We demonstrated how such techniques are useful for thinking about both personality structure and the processes through which personality operates. But as currently implemented, many of the currently used models do not fully capture questions posed by the founders of personality, but a number of emerging techniques, like continuous time modeling, differential equation modeling, and change as outcome models offer exciting opportunities for more nuanced ways of understanding what personality is and how it operates dynamically. 


\section{References}

Allport, G. W. (1937). Personality: A psychological interpretation.

Allport, G. W. (1961). Pattern and growth in personality.

Allport, G. W., \& Odbert, H. S. (1936). Trait-names: A psycho-lexical study. Psychological Monographs, 47(1), i.

Bandura, A. (1986). The explanatory and predictive scope of self-efficacy theory. Journal of Social and Clinical Psychology, 4(3), 359-373.

Bandura, A. (1997). Self-efficacy: The exercise of control. New York: Freeman.

Bandura, A. (1999). Social cognitive theory of personality. Handbook of Personality, 2, 154-196.

Bandura, A. (2006). Guide for constructing self-efficacy scales. Self-Efficacy Beliefs of Adolescents, 5(1), 307-337.

Barenbaum, N. B., \& Winter, D. G. (2008). History of modern personality theory and research. Handbook of Personality: Theory and Research, 3, 3-26.

Baumert, A., Schmitt, M., Perugini, M., Johnson, W., Blum, G., Borkenau, P., ... \& Jayawickreme, E. (2017). Integrating personality structure, personality process, and personality development. European Journal of Personality, 31(5), 503-528.

Beck, E. D., \& Jackson, J. J. (2017). The search for a bridge: Idiographic personality networks. European Journal of Personality, 31, 530-532.

Beck, E. D., \& Jackson, J. J. (2019). Within-Person Variability

Beck, E.D., \& Jackson, J. J. (2020a). A mega-analysis of personality prediction: Robustness and boundary conditions. Manuscript under review. 
Beck, E. D., \& Jackson, J. J. (2020b). Consistency and change in idiographic personality: A longitudinal ESM network study. Journal of Personality and Social Psychology, 118(5), 1080-1100.

Boker, S., Neale, M., \& Rausch, J. (2004). Latent differential equation modeling with multivariate multi-occasion indicators. In Recent developments on structural equation models (pp. 151-174). Springer, Dordrecht.

Borkenau, P., \& Ostendorf, F. (1998). The Big Five as states: How useful is the five-factor model to describe intraindividual variations over time?. Journal of Research in Personality, 32(2), 202-221.

Borsboom, D., \& Cramer, A. O. (2013). Network analysis: an integrative approach to the structure of psychopathology. Annual Review of Clinical Psychology, 9, 91-121.

Borsboom, D., Fried, E. I., Epskamp, S., Waldorp, L. J., van Borkulo, C. D., van der Maas, H. L., \& Cramer, A. O. (2017). False alarm? A comprehensive reanalysis of "Evidence that psychopathology symptom networks have limited replicability" by Forbes, Wright, Markon, and Krueger (2017).

Borsboom, D., Mellenbergh, G. J., \& Van Heerden, J. (2003). The theoretical status of latent variables. Psychological Review, 110(2), 203.

Bos, F. M., Snippe, E., de Vos, S., Hartmann, J. A., Simons, C. J., van der Krieke, L., ... \& Wichers, M. (2017). Can We Jump from Cross-Sectional to Dynamic Interpretations of Networks Implications for the Network Perspective in Psychiatry. Psychotherapy and Psychosomatics, 86(3), 175-177. 
Breil, S. M., Geukes, K., Wilson, R. E., Nestler, S., Vazire, S., Back, M. D., \& Donnellan, M. B. (2019). Zooming into real-life extraversion-How personality and situation shape sociability in social interactions. Collabra: Psychology, 5(1).

Bringmann, L. F., Pe, M. L., Vissers, N., Ceulemans, E., Borsboom, D., Vanpaemel, W., ... \& Kuppens, P. (2016). Assessing temporal emotion dynamics using networks. Assessment, 23(4), 425-435.

Buss, D. M., \& Craik, K. H. (1983). The act frequency approach to personality. Psychological Review, 90(2), 105.

Butner, J. E., Gagnon, K. T., Geuss, M. N., Lessard, D. A., \& Story, T. N. (2015). Utilizing topology to generate and test theories of change. Psychological Methods, 20(1), 1.

Cattell, R. B. (1946a). Description and measurement of personality.

Cattell, R. B. (1946c). Personality structure and measurement. I. The operational determination of trait unities. British Journal of Psychology, 36, 88-102.

Cattell, R. B. (1957). Personality and motivation structure and measurement.

Cervone, D. (2005). Personality architecture: Within-person structures and processes. Annu. Rev. Psychol., 56, 423-452.

Costa, P. T., \& McCrae, R. R. (1985). The NEO personality inventory.

Cramer, A. O., Van der Sluis, S., Noordhof, A., Wichers, M., Geschwind, N., Aggen, S. H., ... \& Borsboom, D. (2012). Dimensions of normal personality as networks in search of equilibrium: You can't like parties if you don't like people. European Journal of Personality, 26(4), 414-431. 
de Haan-Rietdijk, S., Voelkle, M. C., Keijsers, L., \& Hamaker, E. L. (2017). Discrete-vs. continuous-time modeling of unequally spaced experience sampling method data. Frontiers in Psychology, 8, 1849.

Diener, E., Lucas, R. E., \& Scollon, C. N. (2009). Beyond the hedonic treadmill: Revising the adaptation theory of well-being. In The science of well-being (pp. 103-118). Springer, Dordrecht.

Epskamp, S., Waldorp, L. J., Mõttus, R., \& Borsboom, D. (2018). The Gaussian graphical model in cross-sectional and time-series data. Multivariate Behavioral Research, 53(4), 453480.

Fisher, A. J., Medaglia, J. D., \& Jeronimus, B. F. (2018). Lack of group-to-individual generalizability is a threat to human subjects research. Proceedings of the National Academy of Sciences, 201711978.

Fisher, A. J., Reeves, J. W., Lawyer, G., Medaglia, J. D., \& Rubel, J. A. (2017). Exploring the idiographic dynamics of mood and anxiety via network analysis. Journal of abnormal psychology, 126(8), 1044.

Fleeson, W. (2001). Toward a structure-and process-integrated view of personality: Traits as density distributions of states. Journal of Personality and Social Psychology, 80(6), 1011.

Fleeson, W., \& Gallagher, P. (2009). The implications of Big Five standing for the distribution of trait manifestation in behavior: Fifteen experience-sampling studies and a metaanalysis. Journal of Personality and Social psychology, 97(6), 1097.

Forbes, M. K., Wright, A. G., Markon, K. E., \& Krueger, R. F. (2017). Evidence that psychopathology symptom networks have limited replicability. Journal of Abnormal Psychology, 126(7), 969. 
Forbes, M. K., Wright, A. G., Markon, K. E., \& Krueger, R. F. (2019). Quantifying the reliability and replicability of psychopathology network characteristics. Multivariate Behavioral Research, 1-19.

Friedman, J., Hastie, T., \& Tibshirani, R. (2008). Sparse inverse covariance estimation with the graphical lasso. Biostatistics, 9(3), 432-441.

Gates, K. M., \& Molenaar, P. C. (2012). Group search algorithm recovers effective connectivity maps for individuals in homogeneous and heterogeneous samples. NeuroImage, 63(1), 310-319.

Goldberg, L. R. (1981). Language and individual differences: The search for universals in personality lexicons. Review of Personality and Social Psychology, 2(1), 141-165.

Hill, P. L., \& Jackson, J. J. (2016). The invest-and-accrue model of conscientiousness. Review of General Psychology, 20(2), 141-154.

Hopwood, C. J., \& Donnellan, M. B. (2010). How should the internal structure of personality inventories be evaluated?. Personality and Social Psychology Review, 14(3), 332-346.

Jackson, J. J., Hill, P. L., \& Roberts, B. W. (2012). Misconceptions of Traits Continue to Persist: A Response to Bandura. Journal of Management, 38(3), 745-752.

Judge, T. A., Jackson, C. L., Shaw, J. C., Scott, B. A., \& Rich, B. L. (2007). Self-efficacy and work-related performance: The integral role of individual differences. Journal of Applied Psychology, 92(1), 107.

Kruis, J., \& Maris, G. (2016). Three representations of the Ising model. Scientific reports, 6, 34175.

Larson, R., \& Csikszentmihalyi, M. (1983). The experience sampling method. New Directions for Methodology of Social \& Behavioral Science. 
McAdams, D. P. (1997). A conceptual history of personality psychology. In Handbook of Personality Psychology (pp. 3-39).

Mehl, M. R., \& Robbins, M. L. (2012). Naturalistic observation sampling: The Electronically Activated Recorder (EAR).

Mischel, W. (1968). Personality and assessment. Psychology Press.

Mischel, W. (1973). Toward a cognitive social learning reconceptualization of personality. Psychological Review, 80(4), 252.

Mischel, W., \& Shoda, Y. (1995). A cognitive-affective system theory of personality: reconceptualizing situations, dispositions, dynamics, and invariance in personality structure. Psychological Review, 102(2), 246.

Molenaar, P. C. (2004). A manifesto on psychology as idiographic science: Bringing the person back into scientific psychology, this time forever. Measurement, 2(4), 201-218.

Jackson, J. J., Connolly, J. J., Garrison, S. M., Leveille, M. M., \& Connolly, S. L. (2015). Your friends know how long you will live: A 75-year study of peer-rated personality traits. Psychological Science, 26(3), 335-340.

Parrigon, S., Woo, S. E., Tay, L., \& Wang, T. (2017). CAPTION-ing the situation: A lexicallyderived taxonomy of psychological situation characteristics. Journal of Personality and Social Psychology, 112(4), 642.

Piccirillo, M. L., Beck, E. D., \& Rodebaugh, T. L. (2019). A clinician's primer for idiographic research: Considerations and recommendations. Behavior Therapy.

Rauthmann, J. F., Gallardo-Pujol, D., Guillaume, E. M., Todd, E., Nave, C. S., Sherman, R. A., ... \& Funder, D. C. (2014). The Situational Eight DIAMONDS: A taxonomy of major 
dimensions of situation characteristics. Journal of Personality and Social Psychology, 107(4), 677.

Revelle, W., \& Condon, D. M. (2015). A model for personality at three levels. Journal of Research in Personality, 56, 70-81.

Sherman, R. A., Rauthmann, J. F., Brown, N. A., Serfass, D. G., \& Jones, A. B. (2015). The independent effects of personality and situations on real-time expressions of behavior and emotion. Journal of Personality and Social Psychology, 109(5), 872-888.

Shoda, Y., Mischel, W., \& Wright, J. C. (1994). Intraindividual stability in the organization and patterning of behavior: Incorporating psychological situations into the idiographic analysis of personality. Journal of Personality and Social Psychology, 67(4), 674.

Specht, J., Egloff, B., \& Schmukle, S. C. (2011). Stability and change of personality across the life course: The impact of age and major life events on mean-level and rank-order stability of the Big Five. Journal of Personality and Social Psychology, 101(4), 862.

Sosnowska, J., Kuppens, P., De Fruyt, F., \& Hofmans, J. (2019). A dynamic systems approach to personality: The Personality Dynamics (PersDyn) model. Personality and Individual Differences, 144, 11-18.

Wild, B., Eichler, M., Friederich, H. C., Hartmann, M., Zipfel, S., \& Herzog, W. (2010). A graphical vector autoregressive modelling approach to the analysis of electronic diary data. BMC medical research methodology, 10(1), 28.

Wood, D., Spain, S. M., \& Harms, P. D. (in press). Functional approaches to representing the interplay of situations, traits, and behavior. In D. C. Funder, R. A. Sherman, \& J. F. Rauthmann (Eds.), Handbook of Psychological Situations. New York: Oxford. 
Wright, A. G., Gates, K. M., Arizmendi, C., Lane, S. T., Woods, W. C., \& Edershile, E. A. (2019). Focusing personality assessment on the person: Modeling general, shared, and person specific processes in personality and psychopathology. Psychological assessment, 31(4), 502.

Wright, J. C., \& Mischel, W. (1987). A conditional approach to dispositional constructs: the local predictability of social behavior. Journal of Personality and Social Psychology, 53(6), 1159.

Zuckerman., M. (1979). Traits, states, situations, and uncertainty. Journal of Behavioral Assessment, 1, 43-53. 